\title{
EVALUATION OF IMMEDIATE IMPLANT PLACEMENT IN CHRONICALLY INFECTED SITE
}

\author{
Ramy Ragab Elbeialy*
}

\begin{abstract}
To determine the outcome of dental implants inserted immediately in chronically infected sites.

Patients and methods: 40 implants were inserted immediately in chronically infected sites.

Results: Implants were successfully osseo-integrated with a success rate exceeding $90 \%$.

Summary and conclusion: Using the proper protocol to ensure proper debridement of residual infection, Implants can be successfully inserted immediately in chronically infected sites.
\end{abstract}

KEY WORDS: Immediate implants, chronically infected sites, insertion torque.

\section{INTRODUCTION}

Immediate implants are often avoided in areas where infection is present because of the fear of failure. This was so much related to the cases with acute infection but what was questionable is the immediate insertion of implants in chronically infected sites. Recently, comparative studies have shown that similar success rates were reported for implants inserted in previously infected sites compared to implants inserted in non-infected sites. (1) Studies have shown that the presence of chronic infection at the extraction site does not affect osseointegration if all the contaminated area was properly debrided. For proper control of infection, sharp curettage, surgical drills and piezo surgery with copious irrigation are used to ensure proper wound debridement rendering fresh bleeding bone. ${ }^{(2,3)}$ Alveolar ridge resorption following teeth extraction may considerably reduce the residual alveolar bone volume and compromise the favourable positioning of implants required for optimal restoration. The soft tissue architecture is also disturbed overlying the resorbed residual alveolar bone. ${ }^{(4,5)}$ Following the correct clinical indications, the immediate implant placement into extraction sockets avoids this undesirable resorption as well as preservation of the soft tissue architecture overlying the residual alveolar bony plates. ${ }^{(6,7)}$ Additional benefits which are also valued by patients are the avoidance of a two stage procedure by performing the extraction together with immediate implant placement in one setting. It also help to reduce the overall treatment time and early restoration of function.

* Department of Oral and Maxillofacial Surgery, Cairo University 


\section{AIM OF THE STUDY}

To determine the outcome of dental implants inserted immediately in chronically infected sites.

\section{PATIENTS AND METHODS}

A total of 40 implants were immediately placed in chronically infected sockets. All patients were followed up for one year postoperatively. The protocol we followed for immediate placement was as follows:

- Cone beam was done preoperatively to determine the extent of infection, the expected residual alveolar bone volume and architecture as well as the desired implant position.

- Full mouth periodontal treatment was performed 3-5 days before surgery.

Amoxicillin $1 \mathrm{gm}^{*}$ (Glaxosmithkline, Middlesex, United Kingdom) was given twice daily for 3 days before operation and 4 days post-operative.

- Under local anesthesia, extraction was done with minimum trauma using periotomes and small elevators for luxation of teeth. For multirooted teeth, root sectioning was performed using surgical drills to minimize the amount of force applied for luxation and delivery.

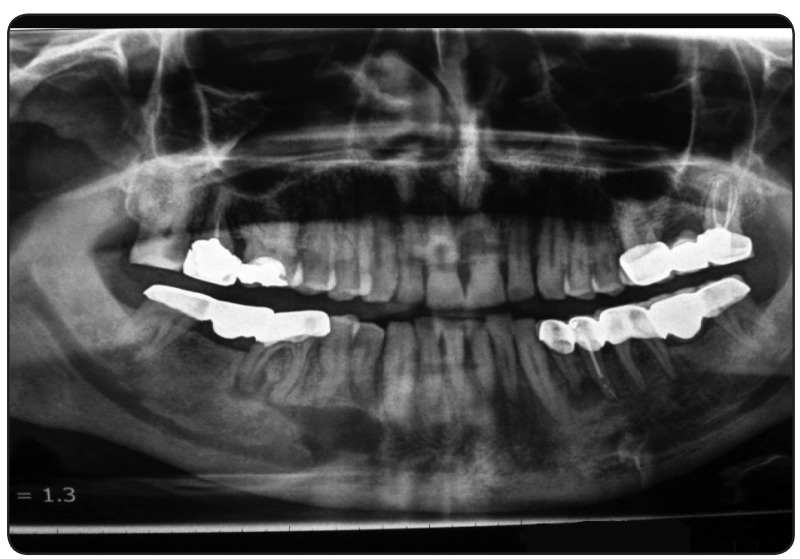

Fig. (1) Showing pre-operative panoramic x-ray showing chronic infection related to lower premolar- molar region bilaterally.
- Removal of pathology was performed using small sharp curettes followed by using piezo electric surgery to shave the bone surrounding the pathology.

- Copious irrigation of the site was performed using saline and hydrogen peroxide to wash out any residual debris from the implantation site.

- Preparation of the osteotomy site was performed using sequential drilling protocol rendering an undersized osteotomy to allow achieving primary stability in the implants through engaging the surrounding walls of the osteotomy as well as extending the osteotomy for 3-5 $\mathrm{mm}$ beyond the apex of the extraction socket whenever possible according to the measurements obtained from the cone beam CT. Implant insertion torque was monitored by graduated adjustable torque ranch to insert all implants. Implants primary stability was monitored by obtaining an immediate osstell reading intraoperatively. Implant primary stability should not be compromised in immediate post-extraction implantation cases. Bone particulate was used as a gap filling material to fill the space around the implants and surrounding bone.

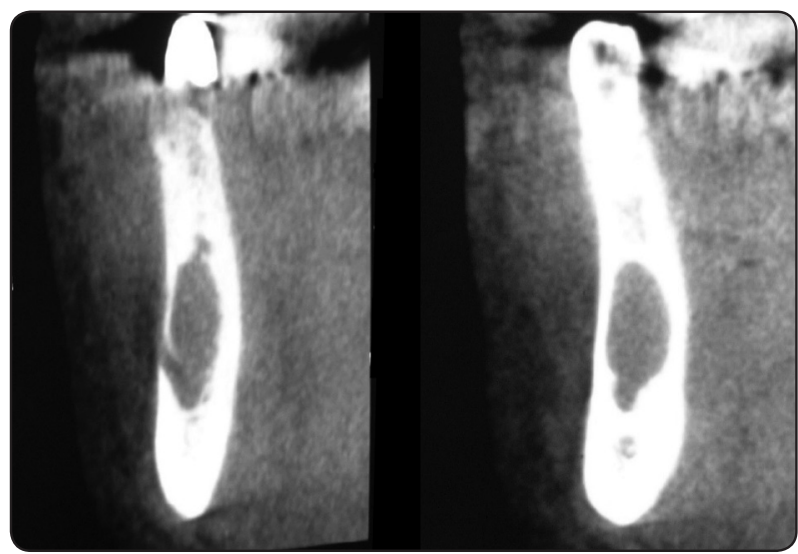

Fig. (2) Showing preoperative CBCT with cross sectional view for the affected sites. 
- After placement of the implant, the defect was filled with autogenous bone collected from the same site through scrapping the buccal cortical bone using very sharp bone scrappers. In sites were the defect was large, Bio-oss (Xenograft)( by Geistlish) was added to the autogenous bone harvested to increase the volume of the graft to completely fill the defect.

- Platelet rich fibrin (PRF) prepared from patients blood according to the standard protocol of 3000 RPM for 12 mins was used to cover the grafted sites.

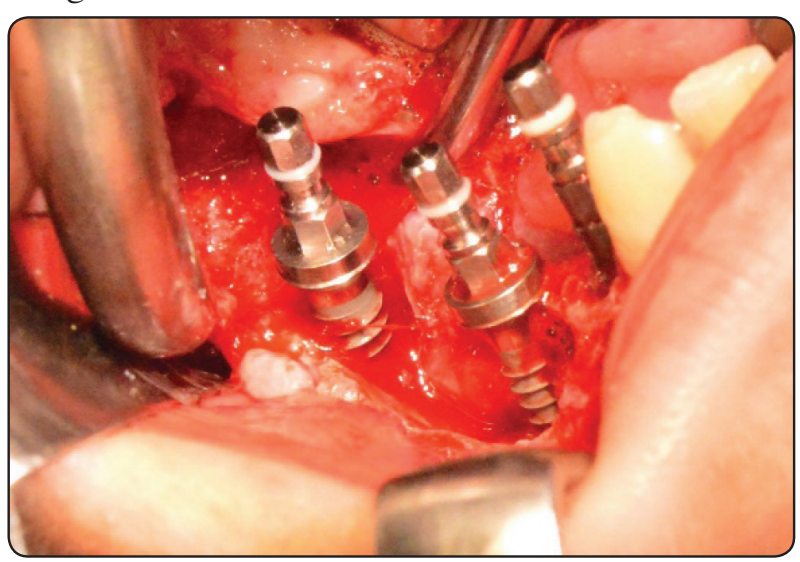

Fig. (3) Showing intra operative clinical photograph of dental implants immediately inserted in chronically infected sockets after manipulation and irrigation.

- Ostell reading was recorded following implant placement.

- Healing collars were secured to cover the implants connection.

- Defect was closed with proper flap suturing. In some cases, collagen membrane was used for guided bone regeneration and in some cases, flap advancement was performed for adequate closure of the wounds.

- Postoperative NSAIDS were prescribed (BRUFEN) TDS for pain control.

- Final loading of all implants were performed at 3 months postoperative in all mandibular implants.

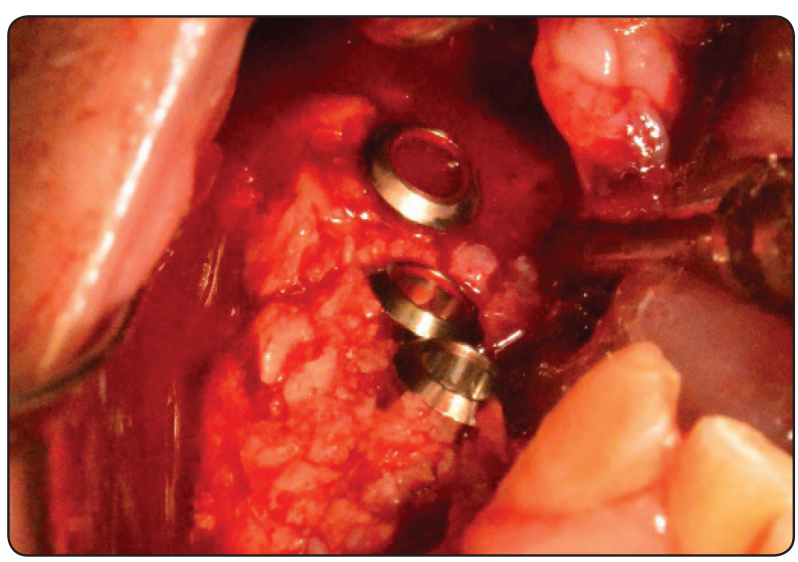

Fig. (4) Showing bony graft filling the defect around the implants

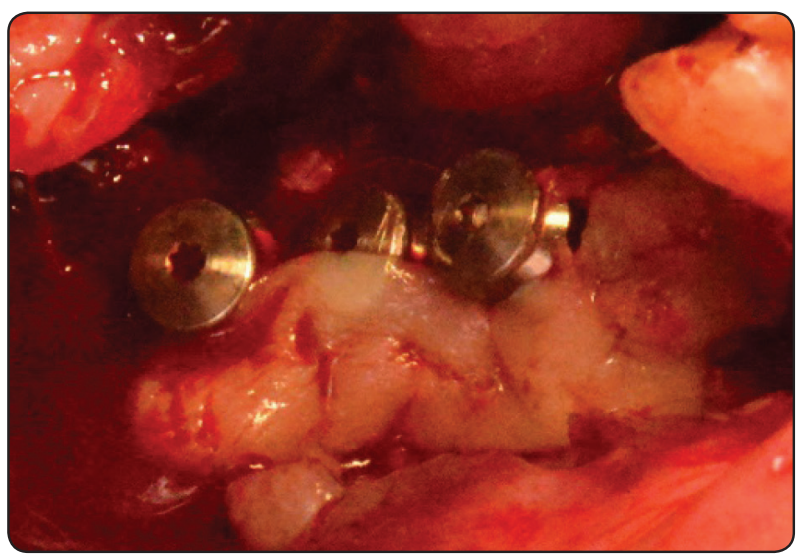

Fig. (5) Showing Platelet rich fibrin covering the grafted site.

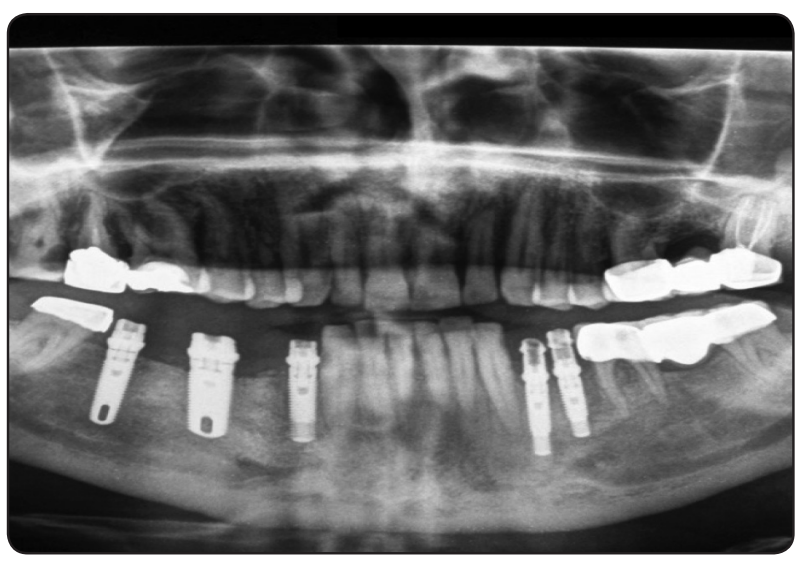

Fig. (6) Showing immediate post operative panoramic xray. 


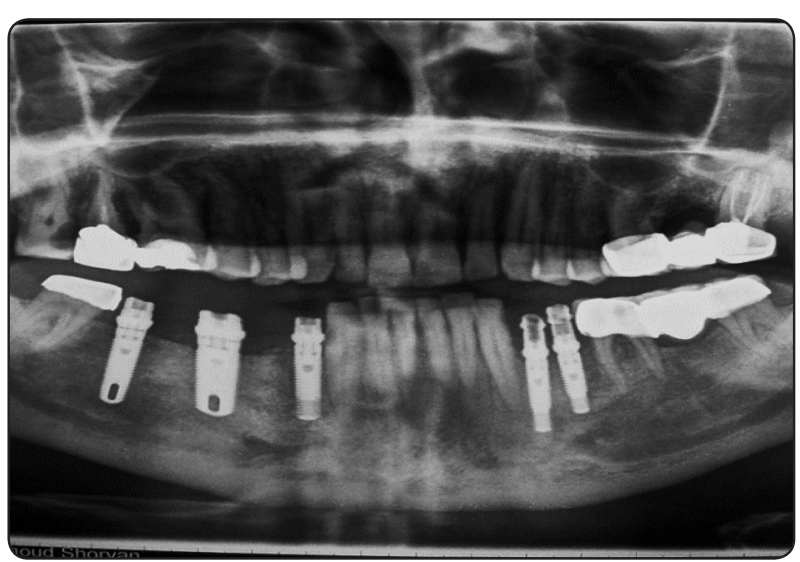

Fig. (7) Showing 6 months post operative panoramic xray.

\section{RESULTS}

The present study was carried out to evaluate the placement of implants in infected sites. A total of 40 cases of immediate post extraction implantation were performed using the previously mentioned protocol. Clinical parameters were used for post implantation observations. These parameters included implant stability (in terms of clinical stability and osstell reading), gingival status (in terms of severe soft tissue dehiscence leading to implant thread exposure) and marginal bone loss. The observations were made post operatively on the $1^{\text {st }}$ day and then on the $1^{\text {st }}, 4^{\text {th }}, 6^{\text {th }}$ and $12^{\text {th }}$ week and then one year. All implants showed successful osseo-integration except four implants.

It was observed that the marginal bone loss was absent on the $1^{\text {st }}$ day and the $1^{\text {st }}$ week in all patients. Bone loss was present in four patients after the $4^{\text {th }}, 6^{\text {th }}$ and $12^{\text {th }}$ weeks. Although marginal bone loss reduced by time but this was non-significant. (Table 1)

Stability was present in all cases at the $1^{\text {st }}$ day, $1^{\text {st }}$ week and $3^{\text {rd }}$ week. All implants showed and insertion torque of more than $40 \mathrm{~nm}$. All implants recorded an immediate post-operative ostell readings of more than 58 ICQ units. Two cases lost their stability at the $4^{\text {th }}$ week post-operatively. These 2 implants showed clinical mobility with slightly swollen gums and where removed immediately with proper irrigation and wash out of any graft material and left for secondary healing. Another two cases lost their stability at the $12^{\text {th }}$ week $(10 \%)$. These 2 implants showed an ostell reading of 66 ICQ units but they were mobile during abutments installation, so they were both removed as well. The difference in stability was non- significant with time. (Table 2)

TABLE (1) Marginal Bone Loss and soft tissue stability.

\begin{tabular}{|c|c|c|c|c|c|}
\hline & $\begin{array}{c}1^{\text {st }} \\
\%\end{array}$ & $\begin{array}{c}1^{\text {st }} \text { week } \\
\%\end{array}$ & $\begin{array}{c}4^{\text {th }} \text { week } \\
\%\end{array}$ & $\begin{array}{c}6^{\text {th }} \\
\% \text { week }\end{array}$ & $\begin{array}{c}12^{\text {th }} \\
\% \text { week }\end{array}$ \\
\hline Prsent & - & - & 10 & 10 & 10 \\
\hline Absent & 100 & 100 & 90 & 90 & 90 \\
\hline Total & 100 & 100 & 100 & 100 & 100 \\
\hline
\end{tabular}

$P=0.91$ (Not significant)

TABLE (2) Implant Stability:

\begin{tabular}{|c|c|c|c|c|c|}
\hline & $\begin{array}{c}1^{\text {st }} \text { day } \\
\%\end{array}$ & $\begin{array}{c}1^{\text {st }} \text { week } \\
\%\end{array}$ & $\begin{array}{c}4^{\text {th }} \text { week } \\
\%\end{array}$ & $6^{\text {th }}$ week & $1^{\text {th }}$ week \\
$\%$
\end{tabular}




\section{DISCUSSION}

Immediate dental implant placement into fresh extraction sockets was shown to be a predictable and successful procedure when proper protocols were followed. Implant placement in chronically infected sites were considered a relative contraindication. Some research used to state that a periapical pathology may be a cause of implant failure. ${ }^{(5,8,9)}$ Thus, many surgeons hesitate in placing the dental implants in infected sites and infection became a relative contraindication for immediate implantation. Aiming to reduce the onset of alveolar bone resorption as well as to decrease the overall treatment time, immediate post extraction implantation has been propagated by some authors. ${ }^{(10,11)}$ Although few clinical data are available on immediate implant placement in infected sites, clinical reports have suggested that the history of the periodontal or endodontic infection is a predictive marker for implant failure. ${ }^{(12-15)}$ Thus, some authors contraindicate the immediate placement of implants in the presence of periapical or periodontal lesions. ${ }^{(16,17)}$

On the other hand, recent publications have stated that immediate implant placement is not contraindicated if the proper surgical protocol was followed to ensure proper debridement of any residual infected tissue. ${ }^{(18)}$ Lindeboom et al ${ }^{(19)}$ carried out a retrospective and randomised study of 50 patients aiming to evaluate the clinical outcome of implants inserted in infected sites. His results showed a success rate of $92 \%$ in immediate implant in infected sites and $100 \%$ in delayed implantation (3 months following extraction). They concluded that immediate implant placement in infected site is a predictable treatment protocol.

In the present study, we performed immediate implant placement in infected site with the prementioned protocol regarding post-extraction bony management using sharp curettes and copious irrigation to ensure leaving healthy bleeding bare bone for immediate implant insertion. The use of preoperative antibiotics is an important tool for the control of infection. ${ }^{(6)}$ Following teeth extraction and proper debridement of residual infected tissue from the extraction socket, implant preparation using undersized osteotomy preparation technique to help achieving high torque of insertion and sufficient primary stability in all implants. In cases requiring grafting of the bony defects, we used autogenous bone alone or in combination with xenograft to increase the volume of the graft material. Platelet rich fibrin was used to cover the grafts and in cases with large defects, resorbable collagen membrane was used for guided bone regeneration. Our study proved a favourable outcome of implants inserted immediately in infected sites. Our study suggests that success is extremely related to the adherence to the protocol of management, but a long term study with bigger sample size and longer follow up period for authentication of this protocol and procedure.

\section{CONCLUSION}

Immediate post extraction implantation is a viable option to maintain the periodontal architecture because of their anatomic compatibility with the dental socket and the possibility of eliminating the residual local contamination. Evidence suggests that implants can be immediately inserted in infected sites. These sites must be properly debrided and irrigated to eliminate residual infection under antibiotic umbrella. Implants should be inserted using undersized osteotomy technique to allow for intimate bone-implant contact and thus achieving adequate primary stability. All implants inserted in this study were successful except four implants. Marginal bone loss was reduced with time but this was non-significant. We can conclude that when utilising the proposed protocol, we can insert implants immediately in infected sites. 


\section{REFERENCES}

1- Waasdrop JA, Evian CI, Mandracchia M. Immediate placement of implants into infected sites: A systematic review of literature. J periodontal;81;801-8.2010.

2- Crespi R, Cappare P, Gherlone E. Fresh socket implants in periapical infected sites in humans. J periodontal ;81;37883.2010

3- Hee HT, Majd ME, Holt RE, Pienkowski D. Better treatment of vertebral osteomyelitis using posterior stabilization and titanium mesh cages. J spinal disorder Tech 15149-156.2002

4- Liljengvist U, Lerner T, Bullmann V, Hackenbrg L, Halm $\mathrm{H}$, Winkelmann W. Titanium cages in the surgical treatment of severe vertebral osteomyelitis. Eur spine 12;606612.2003

5- Kan Jy, Shiotsu G, Rungcharassaeng K, Lozada JL. Maintaining and attenuating periodontal tissues for aesthetic implant placement. J oral implantol 26;35-41.2000

6- Shorpp L, Kostopoulos L, Wenzel A. Bone healing following immediate versus delayed placement of titanium implants into extraction sockets: A prospective clinical study. Int J oral maxillofac implants 18:189-199.2003

7- Werbitt MJ, Goldberg PV. The immediate implant: Bone preservation and bone regeneration. Int $\mathrm{J}$ periodontics Restorative Dent. 12:206-217.1992

8- Bartee BK. Extraction site reconstruction for alveolar ridge preservation. Part 1: Rationale and materials selection. J oral implantol 27:187-93.2001

9- $\quad$ Yang J, Lee HM, Vernino A. Ridge preservation of dentition with severe periodontitis. Compend contin Educ Dent 21:579-83.2000

10- Lazzara RJ. Immediate implant placement into extraction sites: Surgical and restorative advantages. Int J Periodontics Restorative Dent 9:332-43.1989
11- Ohrnell LO, Hirsch JM, Ericsson I, Branemark PI. Single tooth rehabilitation using osseointegration. A modified surgical and prosthodontic approach. Quintessence Int 10:871-6.1988

12- Ayangco L, Sheridan PJ. Development and treatment of retrograde peri-implantitis involving a site with a history of failed endodontic and apicectomy procedures. A series of reports. Int J Oral Maxillofac Implants 16:412-7.2001

13- Oh TY, Yoon J, Wang HL. Management of the implant periapical lesion: A case Report. Implant Dent 12:41-6.2003

14- Karoussis IK, Salvi GE, Heitz-Mayfield LJ, Bragger U, Hammerle CH, Lang NP. Long term implant prognosis in patients with and without a history of chronic periodontitis. A 10 year cohort prospective study of the ITI implant system. Clin Oral Implants Res 14:329-39.2004

15- Polizzi G, Gronder U, Goene R, Hatano N, Henry P, Jackson WJ et al. Immediate and Delayed implant placement into extraction sockets: A 5 year report. Clin implant Dent Relat Res 2:93-9.2000

16- Becker W, Becker BE. Guided tissue regeneration for implants placed into extraction sockets and for implant dehiscence: Surgical techniques and case report. Int J Periodontics Restorative Dent 10:376-91.1990

17- Barzilay I. Immediate Implants: Their current status. Int J Prosthodont 6:169-75.1993

18- Novaes AB Jr, Vidigal GM Jr, Novaes AB, Grisi MF, Polloni S, Rosa A. Immediate implants placed into infected sites; A histomorphometric study in dogs. Int J Oral Maxillofac Implants 13:422-7.1998

19- Lindeboom JA, Tijiook Y, Kroon FH. Immediate placement of implants in periapical infected sites. A prospective randomised study in 50 patients. Oral Surg Oral Med pathol Oral Radiol Endo 101:705-10.2006 